\title{
Survival advantage of siblings and spouses of centenarians in 20th-century Quebec
}

\author{
Valérie Jarry \\ Department of Demography, Université de Montréal \\ valerie.jarry@umontreal.com \\ Alain Gagnon \\ Department of Demography, Université de Montréal \\ Robert Bourbeau \\ Department of Demography, Université de Montréal
}

\begin{abstract}
Longevity runs in families, either through genetic or environmental influences. Using Quebec civil registration and historical Canadian censuses, we compared the longevity of siblings and spouses of 806 centenarians to a group of controls, all born in Quebec at the turn of the 20th century. Our results show that siblings of centenarians, who share balf of their genes and a common childhood environment, lived 3-4 years longer than their birth cohort. However, husbands and wives of centenarians lived 4 and 2.5 years longer than their counterparts of the same sex, respectively, suggesting that longevity is also modulated by shared environment in adulthood.
\end{abstract}

Keywords: longevity, mortality, centenarians, siblings.

\section{Résumé}

L'atteinte des très grands âges est modulée par une composante familiale, qu'elle soit génétique ou environnementale. Par l'entremise de l'État civil du Québec et des recensements canadiens de 1901 et 1911, nous analysons la survie après 40 ans des frères, scurs et conjoints de 806 centenaires nés au Québec au cours de la période 1890-1900. Nos résultats montrent que comparativement à leur cohorte de naissance, les frères et scurs de centenaires, qui partagent la moitié de leur bagage génétique en plus d'un environnement familial commun, vivent en moyenne 3 à 4 années supplémentaires. Cependant, il existe également un avantage de survie des conjoints des centenaires, les époux vivant 4 années de plus que la population générale et les épouses, 2.5 années, révélant qu'une part de la longévité est également attribuable au partage d'un même environnement à l'âge adulte.

Mots-clés : longévité, mortalité, centenaires, fratrie.

\section{Introduction}

The dramatic increase in life expectancy during the last century is unprecedented in human history. Many of the early gains in life expectancy can be attributed to decisive victories against childhood infectious diseases, but in the second part of the 20th century, gains shifted to chronic diseases that essentially affected the elderly (Oeppen and Vaupel 2002). Reduction of death rates above age 65 played a larger role, accounting for $30 \%$ of the improvements (Bourbeau and Smuga 2003). Overall, data from various countries indicate that progress has been greater for women than for men, and more rapid in recent than in earlier decades (Vaupel et al. 1998). 
As mortality rates began to plunge at older ages, centenarians became the fastest growing segment of many industrialized populations (Vaupel and Jeune 1995; Robine and Caselli 2005). In Canada, 151 death certificates indicated an age over 100 in 1959, which is two times the 1921 count. In 2003, 1,597 deaths of centenarians were recorded, ten times the 1959 count (Bourbeau and Desjardins 2006). Verified data from the Canadian Human Mortality Database (CHMD) show a similar trend for Quebec, with 64 centenarian deaths in 1975 and 425 in 2005. As elsewhere, the elderly now benefit from a deceleration in mortality (Thatcher et al. 1998; Vaupel et al. 1998), and recent cohorts of centenarians are surfing on a mortality plateau. A fascinating phenomenon itself, the emergence of centenarians also holds major implications for our society. It is therefore important to understand the conditions predisposing individuals to exceptional survival.

Despite spectacular advances, we still have limited knowledge of old-age survival (Christensen and Vaupel 1996). In addition to genes and biological robustness, lifestyle (e.g., smoking or diet), physical and mental activity, exposure to pathogens or chemicals, and access to medical care and social support are all important determinants of longevity. The general presumption is that adult lifestyle and socioeconomic position give rise to chronic health conditions, which develop over the life course (Elo and Preston 1996). However, as the family of origin generally sets the stage for adult life achievement, research on aging and health is increasingly turning to childhood, where the earliest gains in life expectancy were achieved.

An important part of longevity thus comes from early-life familial influences. The family unit is the primary source of transmission of social, environmental, cultural, biological, and genetic factors that may underlie differences in health and mortality. Parents can indeed increase their children's potential for a long life through favourable genetic endowment or through the provision of beneficial economic resources very early in life (Smith et al. 2009). Siblings also share $50 \%$ of their genes on average (Gagnon et al. 2005) and, to a large extent, the same environmental and social conditions during childhood. They may also influence each other's health and longevity through mutual support in old ages (Mazan and Gagnon 2007).

\section{The familial clustering of exceptional longevity}

The existence of a familial transmission and aggregation of longevity is now well established (Beeton and Pearson 1901; Bell 1918; Pearl 1931; Abbot et al. 1978; Philippe 1978; Bocquet-Appel and Jakobi 1990; Cournil et al. 2000; Gavrilov and Gavrilova 2001; Gavrilov et al. 2002; Atzmon et al. 2005; Caselli et al. 2006; You et al. 2010). Most research in the area has focused on the survival of relatives of individuals who reached advanced ages. A study of Mormon genealogies showed that siblings of probands who have reached the 97th percentile of their cohort in terms of age had a life expectancy 14.8 years longer than that of 5,000 randomly selected individuals within the same population (Kerber et al., 2001). These results are quite similar to those found previously by Gudmundsson et al. (2000) in Icelandic genealogies. In this study, first-degree relatives of probands living to the 95th percentile were found to be almost twice as likely to achieve the 95th percentile compared to controls (Gudmundsson et al., 2000). A study conducted on a sample of 1,655 Pennsylvania Amish born prior to 1890 also showed that parental and siblings' ages at death were significantly correlated, as parents and siblings of long-lived individuals had a high probability of surviving to very old age (Mitchell et al. 2001). Schoenmaker et al. (2006) analyzed the survival experience in Dutch families with at least two long-living siblings. Standardized mortality ratio for siblings of the long-living participants was 0.66 , whereas that of the parents was 0.76 .

In pre-industrial Quebec, the study conducted by Blackburn et al. (2004) recognized a significant association between the ages at death of siblings. This study revealed greater lifespan variability for sisters than for brothers, corroborating observations from Desjardins and Charbonneau (1990) of a higher correlation in ages at death among brothers than among sisters. Mazan and Gagnon (2007) explored the same relationships for individuals born between 1625 and 1704 and also found a high dependency in ages at death among siblings, with reduction in mortality risks of $2.1 \%$ and $1.6 \%$, respectively, for men and women, for each additional year of increase in the average age at death among their siblings. On the other hand, using hierarchical modeling, the authors found very little evidence for a strong parent-offspring association and argued that such association, at least in pre-industrial context, has been generally overemphasized and overestimated.

A number of studies have analyzed the familial component of longevity through the pedigrees of centenarians. Perls et al. (1998) compared the siblings of 102 centenarians with the general population, and found that the survival 
ratio of these siblings increased with age, to such an extent that they were about 4 times as likely to live to age 91 as the siblings of people who died at age 73. Perls and his colleagues (2002a) conducted a second study, in which they compared the survival of siblings of 444 centenarians from the New England centenarians Study (NECS) with the US 1900 cohort. This study revealed that, starting from age 20, brothers of centenarians were 16.95 times more likely to live to age 100 compared to their birth cohort, while the corresponding figure for sisters of centenarians was 8.22. In addition, the death rates of siblings of centenarians were about one-half those of the general population at most ages. Comparable work has been conducted in Okinawa, an island prefecture of southern Japan well known for the longevity of its people and home to one of the highest concentrations of centenarians in the world. In an article published in 2006, B.J. Willcox and colleagues added to this body of research by comparing the survival of siblings of 348 centenarians with that of the 1890 Okinawan general population cohort. A survival advantage for siblings of centenarians, for both men and women, was again reported, with approximately half the mortality of their birth cohort-matched counterparts.

Despite extensive evidence supporting the familial aggregation of longevity, there is less evidence available on the impact of shared environment in adulthood. Such sharing can nevertheless be easily explored by the age at death of spouses (Westendorp and Kirkwood 2001). In an article published in 2000, Gudmundsson et al. (2000) found a positive correlation of death rates between spouses, although the relationship was weak. Blackburn et al. (2004) found a mean age at death of 66.3 years for men whose wife died between 50 and 54 years of age, and 69 years for men whose wife died after 85 years of age, a difference of 2.7 years. The relationship was even stronger for women, with a corresponding difference of 4.3 years. These observations agree with those of Mazan and Gagnon (2007) which confirmed that both men and women benefit from the longevity of their spouses. For men, each additional year of life of their spouse reduced their risk of death by $0.6 \%$ ( $6 \%$ for 10 years), while the corresponding figure was $0.5 \%$ for women ( $5 \%$ for 10 years).

The inclusion of age at death of spouses allows to control for the shared environment in adulthood, because spouses who have shared many aspects of their daily life for several years are likely to benefit from the longevity of one another (Mazan and Gagnon 2007; Drefahl 2010). Nevertheless, although a few studies have stressed the importance of spouse survival on longevity, we have little information on the effect of this component at very old ages, let alone in families of centenarians.

The purpose of this paper is to contribute to the understanding of the association between familial longevity and individual successful aging. We examine the mechanisms that influence the aggregation of longevity in families including at least one centenarian by comparing the survival experience of siblings of centenarians and of spouse of centenarians to that of their respective birth cohorts. The question is: Do siblings and spouses of centenarians live longer than the general population?

\section{Data and methods}

Centenarian information was obtained from a list of registered deaths provided by the Institut de la Statistique du Québec, which contains records on centenarians who died between 1985 and 2005 in the province. Only French Canadian Catholics who were born and who died in Quebec were retained. Age validation of the centenarians was made by linking the baptism certificate, found in the parish registers, to the burial certificate (Beaudry-Godin 2010).

Table 1. Birth year of the centenarians.

\begin{tabular}{cccc}
\hline Birth year & Female & Male & Total \\
\hline 1890 & 40 & 16 & 56 \\
1891 & 50 & 7 & 57 \\
1892 & 64 & 10 & 74 \\
1893 & 61 & 10 & 71 \\
1894 & 61 & 12 & 73 \\
1895 & 67 & 16 & 83 \\
1896 & 73 & 11 & 84 \\
1897 & 66 & 13 & 79 \\
1898 & 70 & 15 & 85 \\
1989 & 74 & 11 & 85 \\
1900 & 49 & 10 & 59 \\
\hline Total & 675 & 131 & 806 \\
\hline
\end{tabular}




\section{Selection of cases and family reconstitution}

We identified 3,100 siblings of centenarians for whom we had information on their date of death. Of these, 2,954 lived at least to age 40, and their average year of birth was 1895. The spouses of centenarians were found in the parish registers, which were made available for the years 1800-1940 by the Projet BALSAC (Université du Québec à Chicoutimi). We could verify if the spouse from the first marriage remained the same throughout life by looking at the death certificate, which includes the name of the husband or the wife of the deceased, along with the civil status. Few marriages ended in separation or widowhood. In the very rare cases where an individual did remarry, the marriage with the longest duration was retained for the analysis. We found 390 dates of death for the original 596 spouses, representing $65 \%$ of our spouse sample. Since our focus is on old-age mortality, and early deaths are not related to the biology of aging (Vaupel 1988; Mazan and Gagnon 2007), only individuals who survived to age 40 were included in our sample. Thus, the final sample is based on 2,954 siblings of centenarians, or 1,541 brothers and 1,413 sisters, as well as 76 wives and 314 husbands.

In order to compare the survival of siblings and of spouses of centenarians to that of their birth cohorts, we used a control sample extracted from the Canadian Families Project five-percent 1901 Canadian Census sample (Sager 2001). We selected from this random sample families with at least one child born between 1885 and 1901. Only French Canadian Catholics who went on to live at least to age 40 were selected. Of this control sample, 3,784 individuals (1,906 women and 1,878 men) were matched to their death records. Note that the average year of birth of the control sample was, as in the case of siblings of centenarians, 1895.

As mentioned previously, we did not find all the deaths of all the individuals who were included in our base sample. The missing death records are due in part to deaths occurring before 1926, i.e., the year of the establishment of the Quebec death register records. They may also be the result of difficulties in identifying individuals, a problem that often occurs when there are errors in the first name or the date of birth. In addition, the high frequency of several names complicated the identification and record linkage processes further, and it is also possible that some individuals who were born in Quebec emigrated and died outside of the province. Finally, it is possible that a few individuals who were retraced in the early 20th century censuses as children were still alive in 2004 (Pilon-Marien et al. 2009).

\section{Estimating the survival function: the non-parametric approach}

We first calculated the mean age at death of siblings and spouses of centenarians, conditional on survival to age 40. Second, we estimated the survival probabilities of these individuals from age 40 to older ages, as well as the associated confidence intervals. These results were then compared to the corresponding estimates obtained for our control sample.

The survival function, denoted $S(t)$, is defined as the probability that an individual survives beyond time $t$. This function can be estimated by

$$
S(t)=P(T>t)=1-F(t)
$$

Survival probabilities from age 40 until age $x$, based on the equations given by Klein and Moeschberger (1997), were computed as follows:

$$
{ }_{a} p_{40}=S_{x}=\prod_{i \leq x}\left(1-\frac{d(i, i+a)}{Y_{i}}\right)
$$

where $d(i, i+a)$ represents deaths between age $i$ and $i+a$ and $Y$, the number of individuals surviving to age $x$.

$S$ is based on the probability that an individual survives to the end of an interval of time, knowing that the individual was present at the beginning of the interval.

The variance of the survival curves was estimated by the Greenwood's formula, and the $95 \%$ confidence intervals were calculated as:

$$
S_{x} \pm 1.96 \cdot S_{x} \sqrt{\sum_{i \leq x} \frac{d(i, i+a)}{Y_{i}\left(Y_{i}-d(i, i+a)\right)}}
$$


The sibling survival curves were compared with the corresponding survival curves of the control group to examine whether centenarian siblings had a higher survival probability compared to the general population.

\section{Results}

Table 2 compares the mean ages at death of siblings and spouses of centenarians with the corresponding estimates for their respective birth cohort, conditional on survival to age 40. For men, the mean age at death was 75.4 years, whereas it was 79.3 years for their female counterparts. As for the control group, the mean ages at death were 71.8 and 75.4 years, respectively, for men and women, resulting in a survival advantage of about 4 years for siblings of centenarians relative to their sex.

Table 2. Mean age at death from age 40 of siblings of centenarians compared to the control population.

\begin{tabular}{lccc}
\hline & $\begin{array}{c}\text { Mean age at death conditional } \\
\text { on survival to age } 40\end{array}$ & $\begin{array}{c}\text { Controls of respective } \\
\text { birth cohort }\end{array}$ & $\begin{array}{c}\text { Excess } \\
\text { years }\end{array}$ \\
\hline Siblings of centenarians & $79.3(78.5-80.0)$ & $75.4(74.8-76.1)$ & 3.9 \\
$\quad$ Female & $75.4(74.7-76.0)$ & $71.8(71.2-72.3)$ & 3.6 \\
Male & $77.9(74.8-81.1)$ & $75.4(74.8-76.1)$ & 2.5 \\
Spouses of centenarians & $75.7(74.9-77.0)$ & $71.8(71.2-72.3)$ & 3.9 \\
Female & & & \\
Male & & & \\
\hline
\end{tabular}

Since the socioeconomic environment during adult life appears to play a significant role in longevity, we took into account the ages at death of the spouses of centenarians. In our analysis, only first marriages were selected, unless the first marriage was of very short duration. This restriction was introduced to take into account long-term marriages only, i.e., where a meaningful influence of shared environment could be observed.

As expected, a survival advantage was also observed for the spouses of centenarians. Conditional on survival to age 40 , the mean ages at death of wives and husbands were 75.7 and 77.9 years, respectively. Husbands of centenarians lived almost 4 years longer than their contemporaries, while the corresponding figure was 2.5 years for women. Contrarily to men, women benefited more from having a centenarian among their siblings than from being married to a centenarian. A t-test was performed and allowed us to conclude that the difference was unlikely due to chance $(\mathrm{p}=0.005)$.

Table 3 shows the survival probabilities, including their 95\% CI values, from age 40 to older ages for the siblings of centenarians compared with their respective birth cohort. As shown in this table, siblings of centenarians experienced a survival advantage throughout their lives relative to their birth cohort and the advantage cumulatively increased at older ages. Sisters of centenarians were 1.6 times as likely to survive from age 40 to age 90 and 2.5 times as likely to survive from age 40 to age 100. As for brothers of centenarians, they were found to be approximately 1.5 times more likely to survive from age 40 to age 80 and nearly twice as likely to reach 90 when compared with men from their birth cohort. The number of men who lived pass 90 years is too small to warrant statistical significance.

Table 3. Survival probabilities from age 40 to higher ages of siblings of centenarians and of the control population.

\begin{tabular}{|c|c|c|c|c|c|c|}
\hline & \multicolumn{3}{|c|}{ Female } & \multicolumn{3}{|c|}{ Male } \\
\hline $\begin{array}{c}\text { Probability } \\
\text { of survival } \\
\text { from age } 40 \\
\text { to age... }\end{array}$ & $\begin{array}{c}\text { Siblings } \\
\text { of centenarians } \\
(95 \% \mathrm{CI})\end{array}$ & $\begin{array}{l}\text { Controls } \\
(95 \% \mathrm{CI})\end{array}$ & $\begin{array}{c}\text { Relative } \\
\text { survival } \\
\text { probability }\end{array}$ & $\begin{array}{c}\text { Siblings } \\
\text { of centenarians } \\
(95 \% \mathrm{CI})\end{array}$ & $\begin{array}{l}\text { Controls } \\
(95 \% \mathrm{CI})\end{array}$ & $\begin{array}{c}\text { Relative } \\
\text { survival } \\
\text { probability }\end{array}$ \\
\hline 50 & $0.95(0.93-0.96)$ & $0.93(0.91-0.94)$ & 1.02 & $0.95(0.94-0.96)$ & $0.93(0.91-0.94)$ & 1.02 \\
\hline 60 & $0.88(0.87-0.90)$ & $0.83(0.81-0.85)$ & 1.07 & $0.87(0.85-0.89)$ & $0.82(0.80-0.84)$ & 1.03 \\
\hline 70 & $0.76(0.74-0.79)$ & $0.67(0.65-0.69)$ & 1.14 & $0.68(0.66-0.70)$ & $0.58(0.55-0.60)$ & 1.18 \\
\hline 80 & $0.54(0.52-0.57)$ & $0.42(0.40-0.44)$ & 1.29 & $0.38(0.36-0.41)$ & $0.26(0.24-0.28)$ & 1.47 \\
\hline 90 & $0.22(0.20-0.24)$ & $0.14(0.12-0.15)$ & 1.61 & $0.09(0.08-0.11)$ & $0.05(0.04-0.06)$ & 1.92 \\
\hline 100 & $0.02(0.015-0.030)$ & $0.01(0.005-0.013)$ & 2.52 & $0.003(0.001-0.007)$ & $0.002(0.0007-0.0053)$ & 1.52 \\
\hline $\mathrm{N}$ & 1413 & 1906 & & 1541 & 1878 & \\
\hline
\end{tabular}




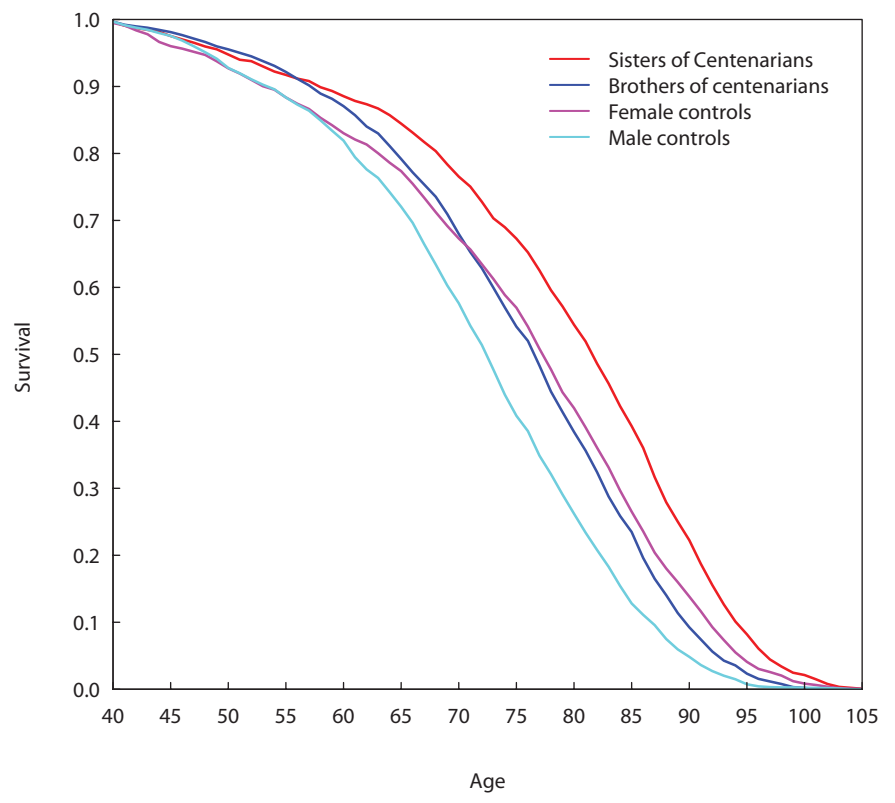

Figure 1. Survival from age 40 of siblings of centenarians compared to the controls.

Survival curves from age 40 for siblings of centenarians (men and women) compared with their respective birth cohorts are shown in Figure 1. The survival probabilities demonstrate that siblings of centenarians experienced a longer life than the general population and kept this advantage through very old ages $(p=0.001)$. For sisters of centenarians, the median life expectancy was about 4 years higher (82 years) when compared with women from their birth cohort (78 years). As for brothers of centenarians, the survival advantage was also considerable, their median age at death being 77 years compared to 73 years for men in the general population.

Figure 2 displays survival curves for spouses of centenarians conditional on survival to age 40 compared with their respective birth cohorts, as well as with siblings of centenarians. Wives of centenarians experienced a survival advantage throughout life relative to their birth cohort. Nonetheless, sisters of centenarians appear to have the longest lives among all three groups. The number of male centenarians, however, was too small to yield reliable estimates for their spouses. For husbands of centenarians, survival curves show a significant survival advantage compared to the control population $(\mathrm{p}=0.001)$. We can also observe that before the age of 75 , they even experienced a lower mortality than the brothers of centenarians. There is, however, a crossover in the survival functions at age 75 approximately, and after that age, brothers of centenarians had a lower mortality and more chance to achieve very old age than husbands of centenarians did.

Further, we hypothesized that the longer the duration of the marriage, the greater was the effect of sharing a common environment on longevity. As shown in Figure 3, spouses whose marriage before age 40 had lasted at least 15 years survived longer than those whose union lasted less than 15 years, although the result is only marginally significant $(\mathrm{p}=0.0842)$.

Subsequently, we decomposed the effect of the centenarian's gender on the longevity of their siblings by sex in order to see whether having a centenarian brother offered higher chances of living to an old age than having a sister who achieved 100 years. In other words, the question is: Is it more beneficial to have a sister or a brother who lives to age 100 ? As it turns out, if women benefit from having a centenarian among their siblings, the sex of that sibling brings no additional influence on their survival (Fig. 4). However, for a man, having a centenarian brother is more beneficial to survival than having a centenarian sister, the difference being statistically significant $(\mathrm{p}=0.001)$.

\section{Discussion}

The results of our survival analysis demonstrate a strong familial component to longevity. It seems undeniable that having or not having a centenarian sibling is a powerful determinant of survival after age 40 for both men and women. These results agree with those of Perls et al. (1998, 2002a) and B.J. Willcox et al. (2006), who proposed that siblings of centenarians experience a favourable survival profile throughout their lives. 

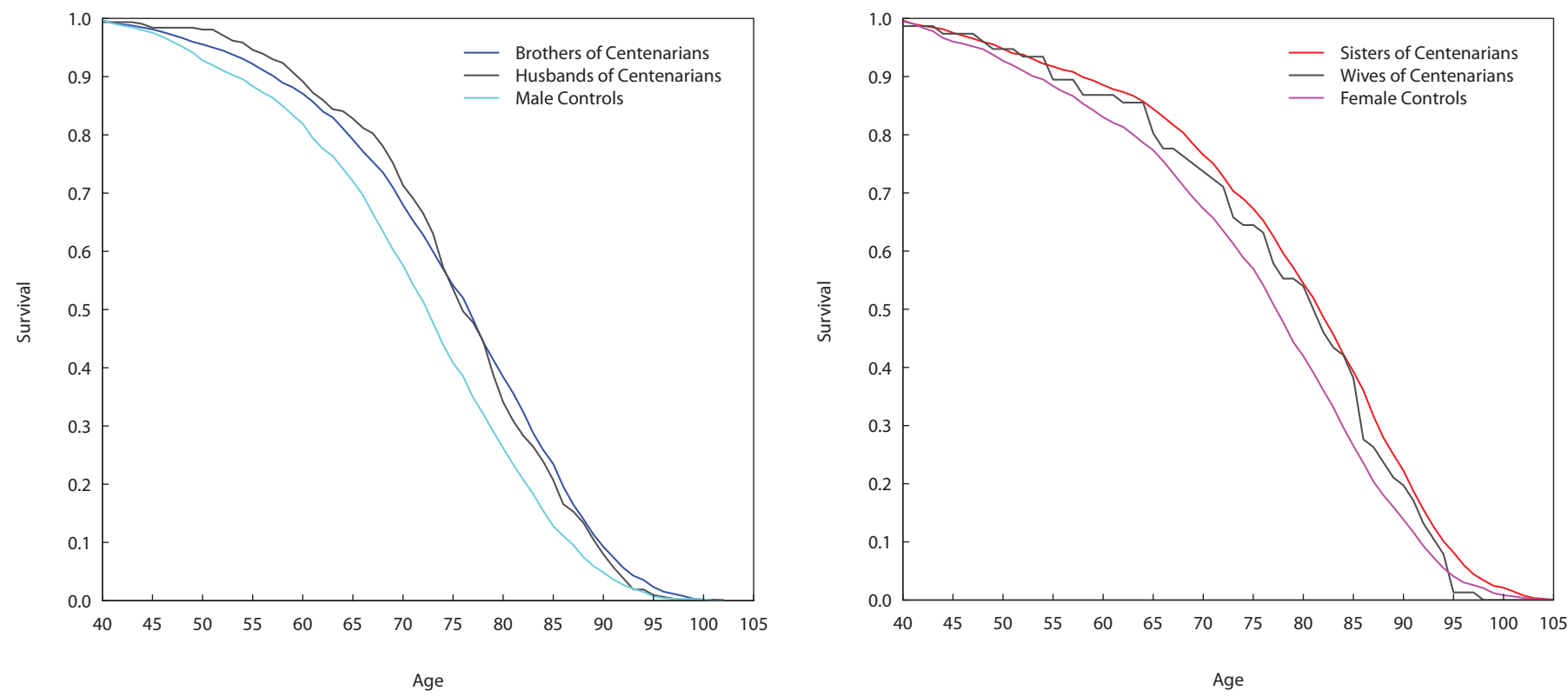

Figure 2. Survival from age 40 of female and male spouses and siblings of centenarians, respectively, compared to the controls.

It is not surprising to observe an association between siblings' life duration, as they share about $50 \%$ of their genes. Overall, studies have indicated that a modest amount of about $25 \%$ of the variation in human lifespan may be genetically influenced, whereas almost $75 \%$ could be attributable to environmental factors (Christensen and Vaupel 1996; Herskind et al. 1996; Ljungquist et al. 1998; Cournil et al. 2000; Kerber et al. 2001). However, these studies were conducted in populations where few individuals have reached their 85th birthday. For people reaching very old ages, genetics may take a larger share of their survival (Perls et al. 2002b). In this regard, Hjelmborg and colleagues (2006), analyzing the survival of Danish, Swedish and Finnish twins born between 1870 and 1910, have recently shown that the genetic component tends to increase with age (Hjelmborg et al. 2006).

Genetic research has highlighted an impressive selection of genes that may be excellent candidates in the modulation of lifespan. Biomolecular studies of centenarians have allowed the identification of genetic variants that promote or prevent the achievement of human longevity. A study of a population of 338 French centenarians and 164 control individuals has shown an association between the apolipoprotein E gene and longevity outcomes (Schachter

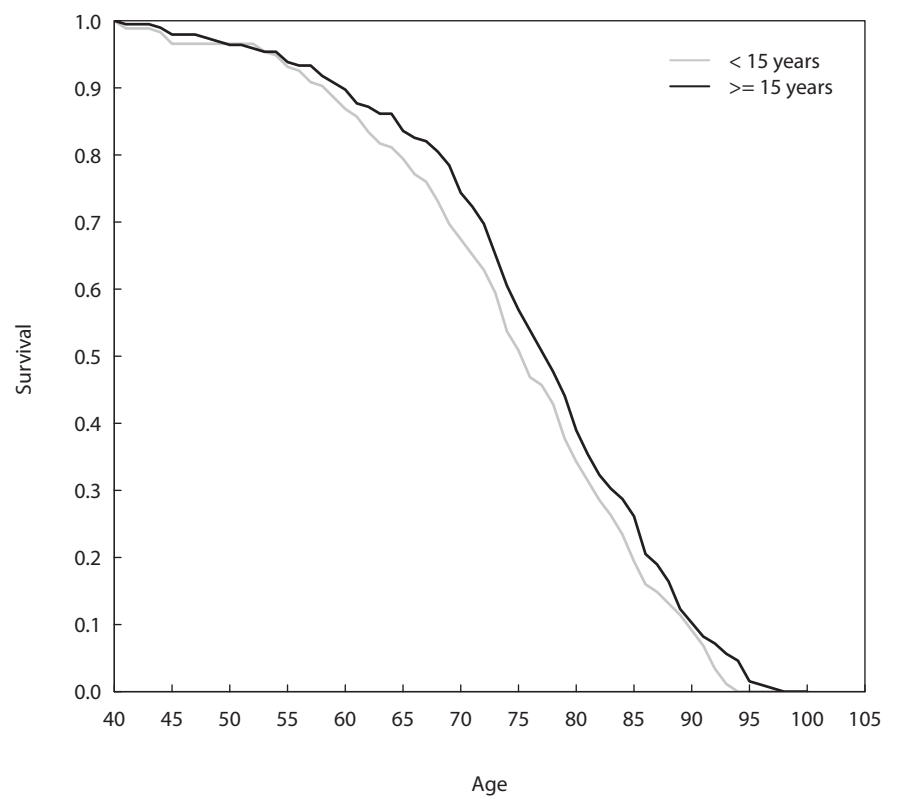

Figure 3. Survival of spouses of centenarians by duration of marriage. 

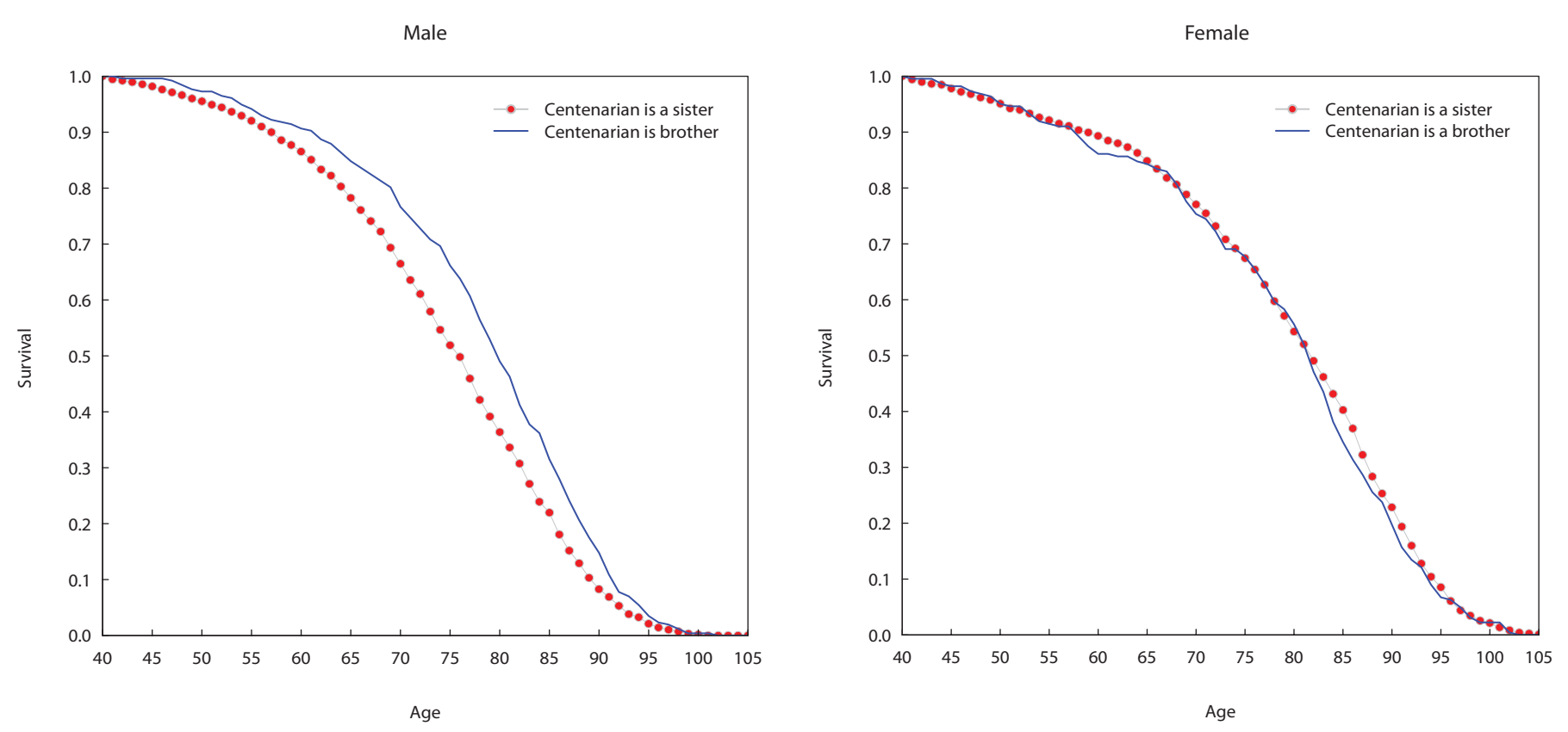

Figure 4. Survival of male and female siblings of centenarians, respectively, according to the sex of the centenarian.

et al. 1994). The Apolipoprotein E gene, also known as the "frailty" gene, is one of the most studied genes in longevity and health research, as it affects the age-specific susceptibility to death (Christensen et al. 2006). The results indicate that the $\varepsilon 4$ allele of APOE, which is associated with an increased risk of coronary heart and Alzheimer's diseases, is significantly less frequent in centenarians than in controls, while the frequency of the $\varepsilon 2$ allele, associated with a longer life and preserved cognitive functions, is significantly increased. Further research is needed to understand the likely impact of genes on human longevity, and although this influence is practically certain, it is also known to be modulated and modified by environmental influences. Thus, because siblings not only share a similar genetic background but also common environments, habits, and behaviours, it is plausible that the survival advantage of siblings of centenarians could be in part the result of exposure to the same environment during childhood (Crow and Johnson 2005; C.D. Willcox et al. 2006).

Another key result of our paper is the higher benefit of having a brother who lived to age 100 for men in comparison with having a sister who lived to that age, a sex-specific benefit not seen for sisters of centenarians. Several factors related to the time period and the historical context could explain these results. Centenarians' families originated mostly in rural areas, where brothers tended to work together, migrate together, and settle on land near each other. Many of them became farmers themselves in adulthood, an occupation associated with lower mortality (Gagnon et al. 2011). On the other hand, women, who did not inherit farmland, were more likely to move to the city or to migrate to their spouse's familial land (Gossage 1999). Mutual aid and familial solidarity was likely more prevalent among male siblings in this patrilocal society, right from the outset of colonization. Mazan and Gagnon (2007) found that associations in ages at death were stronger for brothers living in the same region than for sisters, suggesting that mutual support among congregating groups of male siblings living in close geographical proximity was key to survival on the vast Canadian frontier.

The inclusion of spouses' ages at death as a predictor of longevity adds a new dimension to previous studies that have focused almost exclusively on first-degree relatives. We have seen that the survival of spouses, who are unrelated genetically, may serve as an indicator of environmental risk. Our results show a significant survival benefit for husbands of centenarians compared to the general population, suggesting that a shared common environment in adulthood affects their longevity and reflects a similar mortality risk. However, after age 75 the survival correlation between spouses lessens, and men seem to benefit more from being a sibling than a spouse of a centenarian. As for the wives of centenarians, despite their small sample size, they also experienced a longer life in comparison with their female counterparts in the general population. Several theories have been proposed to explain the similarity in spouse mortality patterns, one of the most important being the shared resources hypothesis, proposing that sharing the same environment within the household leads to shared mortality risks. Indeed, since spouses are generally exposed to the 
Jarry et al.: Survival advantage of siblings and spouses of centenarians in 20th-century Quebec

same socio-sanitary conditions, the same dietary habits, and the same socioeconomic environment, they will tend to have a similar life duration (Smith and Zick 1994). Therefore, spouse survival should depend on the duration of the marriage; the longer the marriage, the greater the similarity of ages at death should be, suggesting a cumulative effect of the common marital environment.

Husbands' and wives' concordance in survival may not only be due to exposure to the same environment during their years of cohabitation, but may also result from "assortative mating." This theory suggests that people with similar characteristics or lifestyles have a greater chance of becoming a couple (Lillard and Panis 1996). However, our results show that the time spent in union before age 40 also has an influence. Spouses who had lived in cohabitation for a period of 15 years or more lived longer than those whose union was less than 15 years, revealing that sharing a marital environment causes progressive similarities in mortality risk as spouse pairs married for longer periods experienced an increased concordance in their life duration. Another possible explanation for the survival advantage of spouses of centenarians, particularly husbands, lies in the fact that they do not experience an increased risk of mortality associated with the loss of a spouse.

One drawback of this study, as previously discussed, is that we could not include in our analysis all the siblings and spouses of our 806 centenarians, because of a lack of information about their dates of death. However, there is no reason to believe that individuals for whom we did not find the death record differ from those for whom this information is available, and the reasons why we could not find all deaths are identical for both samples. Eventually, additional sources from parish registers will either confirm this hypothesis or eliminate possible bias. Another limitation of this study is the small size of the sample of female spouses of centenarians. In our future work, replication of these results with a larger sample of centenarians should lead us to a better verification of the statistical significance of these observations.

This study of survival of siblings and spouses of centenarians leads to several important findings, and is a step closer to understanding the mechanisms modulating the human lifespan. Although our study does not delineate the specific contribution of genes and environmental factors involved in achieving old age, it indicates that the etiology of longevity probably comprises a complex network of interactive genetic, environmental, and possibly stochastic factors. Distinguishing real genetic effects on exceptional longevity is complex, because siblings not only have a similar genetic heritage but also share environmental factors early in life that may have strong effects throughout life. In addition, environment in adulthood plays a major role in survival, and the inclusion of spouses in our analysis provides a means to account for the impact of shared environment in adulthood. Nevertheless, although the environmental component shared by spouses seems primarily responsible for the shared survival advantage up to the mean age at death, it seems to play a less prominent role in achieving the oldest ages. In other words, what appears to allow living until the average age for men is predominantly the result of a shared environment in adulthood, while shared living conditions in childhood and genetics could explain the advantage of brothers of centenarians compared with spouses of centenarians in achieving old ages. These results support the hypothesis that genes may exert a substantial influence on the ability to achieve exceptional old age.

\section{Acknowledgments}

This study was supported by a doctoral scholarship (Jarry) and by a grant (Gagnon and Bourbeau) from the Social Sciences and Humanities Research Council of Canada. The authors are grateful to Jean-Marc Fix for his helpful suggestions provided on an earlier version of this paper. The authors would also like to thank the anonymous reviewers as well as the participants of the IV Living to 100 Symposium and the 2011 Meeting of the Population Association of America for their valuable comments.

\section{References}

Abbott, M.H., H. Abbey, D.R. Bolling, and E.A. Murphy. 1978. The familial component in longevity: A study of offspring of nonagenarians. III. Intrafamilial studies. American Journal of Medical Genetics 2(2):105-120.

Atzmon, G., M. Rincon, P. Rabizadeh, and N. Barzilai. 2005. Biological evidence for inheritance of exceptional longevity. Mechanisms of Ageing and Development Journal 126(2):341-345. 
Beaton, M., and K. Pearson.1901. On inheritance of the duration of life, and on the intensity of natural selection in man. Biometrika:50-89.

Beaudry-Godin, M. 2010. La démographie des centenaires québécois: validation des âge au décès, mesure de la mortalité et composante familiale de la longévité. PhD Diss. University of Montreal.

Bell, A.G. 1918. The duration of life and conditions associated with longevity: A study of the Hyde genealogy. Washington, DC: Genealogical Records Office.

Blackburn, M.-E., R. Bourbeau, and B. Desjardins. 2004. Hérédité et longévité au Québec ancien. Cabiers québécois de démographie 33(1):9-28.

Bocquet-Appel, J.P., and L. Jakobi. 1990. Familial transmission of longevity. Annals of Human Biology 17:81-95.

Bourbeau, R., and M. Smuga. 2003. La baisse de la mortalité : Les bénéfices de la médecine et du développement, in La démographie québécoise: Enjeux du XXIe siècle, edited by V. Piché and C. Le Bourdais. Paramètres. Montreal: Les Presses de l’Université de Montréal, pp. 24-65.

Bourbeau, R., and B. Desjardins. 2006. Mortality at extreme ages and data quality: The Canadian experience, in Human Longevity, Individual Life Duration and the Growth of the Oldest-Old Population, edited by J.-M. Robine, E.M. Crimmins, S. Horiuchi, and Zeng. Springer International Studies in Population 4, pp. 167-185.

Caselli, G., L. Pozzi, J.W. Vaupel, L. Deiana, G. Pes, C. Carru, C. Franceschi, and G. Baggio. 2006. Familial clustering in Sardinian longevity: A genealogical approach. Experimental Gerontolology 41:727-736.

Christensen, K., and J.W. Vaupel. 1996. Determinants of longevity: Genetic, environmental and medical factors. Journal of Internal Medicine 240(6):333-341.

Christensen, K., T. Johnson, and J.W. Vaupel. 2006. The quest for genetic determinants of human longevity: Challenges and insights. Nature Reviews Genetics 7(6):436-448.

Cournil, A., J. Legay, and F. Schachter. 2000. Evidence of sex-linked effects on the in-heritance of human longevity: A population-based study in the Valserine valley (French Jura), 18-20th centuries. Proceedings of the Royal Society 267:1021-1025.

Crow, J.F., and T.E. Johnson. 2005. Comments. Research on Environnmental Effects in Genetic Studies of Aging, special issue, Journal of Gerontology 60B(Series B):7-11.

Desjardins, B., and H. Charbonneau. 1990. L’héritabilité de la longévité. Population 45(3):603-616.

Drefahl, S. 2010. How does the gap between partners affect their survival? Demography 47(2):313-326.

Elo, I.T., and S.H. Preston. 1996. Educational differentials in mortality: United States, 1979-85. Social Science and Medicine 42(1):47-57.

Gagnon, A., J. Beise, and J.W. Vaupel. 2005. Genome-wide identity-by-descent sharing among CEPH siblings. Genetic Epidemiology 29:215-224.

Gagnon, A., M. Tremblay, H. Vézina, and J. Seabrook. 2011. Once were farmers: Occupation, social mobility, and mortality during industrialization in Saguenay-Lac-Saint-Jean, Quebec 1840-1971. Explorations in Economic History 48:429-440.

Gavrilov, L.A., and N.S. Gavrilova. 2001. Étude biodémographique des déterminants familiaux de la longévité humaine. Population 56(1-2):225-252.

Gavrilov, L.A., N.S. Gavrilova, S.J. Olshansky, and B.A. Carnes. 2002. Genealogical data and the biodemography of human longevity. Social Biology 49:160-173.

Gossage, P. 1999. Families in Transition, Industry and Population in Nineteenth-Century Saint-Hyacinthe. Montreal and Kingston: McGill-Queen's University Press.

Gudmundsson, H., D. Gudbjartsson, D. Frigge, J. Gulcher, and K. Stefansson. 2000. Inheritance of human longevity in Iceland. European Journal of Human Genetics 8(10):743-749. 
Jarry et al.: Survival advantage of siblings and spouses of centenarians in 20th-century Quebec

Herskind, A.M., M. McGue, N.V. Holm, T.I. Sorensen, B. Harvald, and J.W. Vaupel. 1996. The heritability of human longevity: A population-based study of 2,872 Danish twin pairs born 1870-1900. Human Genetics 97:319-323.

Hjelmborg, J., I. Iachine, A. Skytthe, J.W. Vaupel, M. McGue, M. Koskenvuo, J. Kaprio, N. Pedersen, and K. Christensen. 2006. Genetic influence on human lifespan and longevity. Human Genetics 119:312-321.

Kerber, R.A., E. O'Brien, K.R. Smith, and R.M. Cawthon. 2001. Familial excess longevity in Utah genealogies. Journal of Gerontology 56A:B130-B139.

Klein, J.P., and M.L. Moeschberger. 1997. Survival Analysis: Techniques for Censored and Truncated Data. New York: Springer.

Lillard, L.A., and C.W.A. Panis. 1996. Marital status and mortality: The role of health. Demography 33:313-327.

Ljungquist, B., S. Berg, J. Lanke, G. McClearn, and N. Pedersen. 1998. The effect of genetic factors for longevity: A comparison of identical and fraternal twins in the Swedish twin registry. Journal of Gerontology 53:441-446.

Mazan, R., and A. Gagnon. 2007. Familial and environmental influences on longevity in a pre-industrialized population. Population 62(2):271-292.

Mitchell, B.D., W. Hsueh, T.M. King, T.I. Pollin, J. Sorkin, A.A. Schaffer, and A.R. Shuldiner. 2001. Heritability of life span in the old order Amish. American Journal of Medical Genetics 102:346-352.

Oeppen, J., and J.W. Vaupel. 2002. Broken limits to life expectancy. Science 296:1029-1031.

Pearl, R. 1931. Studies on human longevity IV. The inheritance of longevity: Preliminary Report. Human Biology 3:245-269.

Perls, T., E. Bubrick, C. Wager, J. Vijg, and L. Kruglyak. 1998. Siblings of centenarians live longer. The Lancet 351:1560.

Perls, T., L. Kunkel, and A.A. Puca. 2002a. The genetics of exceptional human longevity. Journal of Molecular Neuroscience 19:233-238.

Perls, T., J. Wilmoth, R. Levenson, M. Drinkwater, H.B.M. Cohen, E. Joyce, S.J. Brewster, L. Kunkel, and A.A. Puca. 2002b. Life-long sustained mortality advantage of siblings of centenarians. Proceedings of the National Academy of Sciences 99:8442-8447.

Philippe, P. 1978. Familial correlations of longevity: An isolate-based study. American Journal of Medical Genetics 2:121-129.

Pilon-Marien, L., A. Gagnon, B. Desjardins, and R. Bourbeau. 2009. Conditions de vie durant l'enfance et longévité: évaluation d'une base de données créée a partir du recensement canadien de 1901 et de l'état civil québécois. Cabiers québécois de démographie 38(1):171-191.

Robine, J.M., and G. Caselli. 2005. An unprecedented increase in the number of centenarians. Genus 61(1):57-82.

Sager, E.W. 2001. Introduction: The Canadian Families projects. Journal of Family History 26(2):157-161.

Schachter, F., L. Faure-Delanef, F. Guenot, H. Rouger, P. Froguel, L. Lesueur-Ginot, and D. Cohen. 1994. Genetic associations with human longevity at APOE and ACE loci. Nature Genetics 6:29-32.

Schoenmaker, M., A. DeCraen, P. DeMeijer, M. Beekman, G. Blauw, P. Slagboom, and R. Westendorp. 2006. Evidence of genetic enrichment for exceptional survival using a family approach: The Leiden Longevity Study. European Journal of Human Genetics 14:79-84.

Smith, K.R., and C.D. Zick. 1994. Linked lives, dependent demise? Survival analysis of husbands and wives. Demography 31(1):81-93.

Smith, K.R., G.P. Mineau, G. Garibotti, and R. Kerber. 2009. Effects of childhood and middle-adulthood family conditions on later-life mortality: Evidence from the Utah Population Database, 1850-2002. Social Science and Medicine 68(9):1649-1658. 
Thatcher, A.R., V. Kannisto, and J.W. Vaupel. 1998. The Force of Mortality at Ages 80 to 120. Odense: Odense University Press.

Vaupel, J.W. 1988. Inherited frailty and longevity. Demography 25(2):277-287.

Vaupel, J.W., and B. Jeune. 1995. The emergence and proliferation of centenarians, in Exceptional Longevity: From Prehistory to the Present, edited by B. Jeune and J.W. Vaupel. Rostock: Odense University Press.

Vaupel, J.W., J.R. Carey, K. Christensen, T.E. Johnson, A.I. Yashin, N.V. Holm, I.A. Iachine, V. Kannisto, A.A. Khazaeli, P. Liedo, V.D. Longo, Y. Zeng, K.G. Manton, and J. Curtsinger. 1998. Biodemographic trajectories of longevity. Science 280:855-860.

Westendorp, R.G., and L. Kirkwood. 2001. La transmission héréditaire de la longévité en lignes maternelle et paternelle. Population 56(1-2):253-268.

Willcox, B.J., C.D. Willcox, Q. He, D.J. Curb, and M. Suzuki. 2006. Siblings of Okinawan centenarians share lifelong mortality advantages. Journal of Gerontology 61A(4):345-354.

Willcox, C.D., B.J. Willcox, W-C. Hsueh, and M. Suzuki. 2006. Genetic determinants of exceptional human longevity: Insights from the Okinawan Centenarians Study. Age 28(4):313-332.

You, D., D. Gu, and Z. Yi. 2010. Familial transmission of human longevity among the oldest-old in China. Journal of Applied Gerontology 29(3): 308-332. 